\title{
Corrosion Resistance of Super-Hydrophobic Coating on AZ31B Mg Alloy
}

\author{
Zhengwei Song ${ }^{1}$, Zhihui Xie ${ }^{2, *}$, Lifeng Ding ${ }^{l}$, Yike Zhang ${ }^{1}$ \\ ${ }^{1}$ Department of Chemistry and Chemical Engineering, Taiyuan Institute of Technology, Taiyuan \\ 030024, Shanxi, China \\ ${ }^{2}$ Chemical Synthesis and Pollution Control Key Laboratory of Sichuan Province, China West Normal \\ University, Nanchong 637002, Sichuan, China \\ *E-mail: zhxie@cwnu.edu.cn
}

doi: $10.20964 / 2018.07 .29$

Received: 31 March 2018 / Accepted: 8 May 2018 / Published: 5 June 2018

\begin{abstract}
A super-hydrophobic coating was prepared on AZ31B Mg alloy in this paper. Electroless Ni-P coating as the inner layer was deposited on the AZ31 substrate via an electroless planting process, and $\mathrm{Cu}$ was electroplated as the intermediate layer. Then, the electroplating Ni method was employed to form the micro/nano structure, and the super-hydrophobic coating was prepared after the composite coating modified by stearic acid. The modified coating exhibited super-hydrophobic properties with a static water contact angle of $155^{\circ}$. Potentiodynamic polarization and electrochemical impedance spectroscopy (EIS) tests were conducted in $3.5 \mathrm{wt} \% \mathrm{NaCl}$ solution at room temperature. The test results indicated that the corrosion resistance of AZ31 was improved significantly by this superhydrophobic coating. The super-hydrophobic samples had much more corrosion resistance in comparison with freshly prepared samples.
\end{abstract}

Keywords: Corrosion resistance; Super-hydrophobic; Mg alloy

\section{FULL TEXT}

(C) 2018 The Authors. Published by ESG (www.electrochemsci.org). This article is an open access article distributed under the terms and conditions of the Creative Commons Attribution license (http://creativecommons.org/licenses/by/4.0/). 